\title{
Diarrhea and constipation in hospitalized patients treated with fiber-exclusive enteral therapy: longitudinal study
}

\author{
Mayara Alvarenga ${ }^{1}$, Poliana Soares ${ }^{1}$, and Lívia Ferreira ${ }^{2}$ \\ ${ }^{1}$ Affiliation not available \\ ${ }^{2}$ Universidade Federal de Lavras
}

November 6, 2020

\begin{abstract}
Background and objectives: Studies analyzing the frequency of diarrhea and constipation with exclusive enteral nutrition therapy (ENT) enriched with fibers assessing the time effect in clinical outcomes are scarce. So, this was the aim of the present study. Methods: This is a prospective study carried out in hospitalized patients who were fed exclusively on ENT for at least seven days. Those patients were followed daily until reaching 14 days of exclusive ENT diet. The frequency of diarrhea and constipation, the data related to the ENT, the liquids and the medicines received were logged daily. Generalized Estimated Equation was used for statistical analysis $(\mathrm{p}<0.05)$. Results: The sample was of 28 patients $(64.21 \pm 17.70$ years and $75 \%$ men $)$, 15 patients remained until the end of the study. The percentage of diarrhea was $3.6 \%$ to $14.3 \%$, and constipation was $32.1 \%$ to $0 \%(\mathrm{p}=0.035)$. Normal intestine function was more frequent and increased during the study $(\mathrm{p}=0.001)$. Patients with diarrhea and constipation presented lower infusion speed, dietary volume and adequacy of total fibers $(\mathrm{p}<0.05)$. The daily medication was the only variable that remained associated to diarrhea $(\beta=0.125 ; \mathrm{p}=0.04)$ after multivariated analyses. Age $(\beta=-0.021 ; \mathrm{p}<0.001)$ and liquids $(\beta=-0.001 ; \mathrm{p}<0.001)$ were inversely associated to constipation. The use medicines that reduced intestine motility was also associated with constipation $(\mathrm{p}<0.001)$. The prevalence of patients without gastrointestinal dysfunction using fiberenriched diet was more expressive during the study. Conclusion: Age, medication and liquids were associated to both diarrhea and constipation.
\end{abstract}

\section{Hosted file}

Livia-2.pdf available at https://authorea.com/users/373786/articles/491383-diarrhea-andconstipation-in-hospitalized-patients-treated-with-fiber-exclusive-enteral-therapylongitudinal-study

\section{Hosted file}

figure 1.pdf available at https://authorea.com/users/373786/articles/491383-diarrhea-andconstipation-in-hospitalized-patients-treated-with-fiber-exclusive-enteral-therapylongitudinal-study 